\title{
A CPW-fed Tomb Shaped Antenna for UWB Applications
}

\author{
Akanksha Upadhyay, Rajesh Khanna
}

\begin{abstract}
In this paper a Coplanar Waveguide (CPW) fed tomb shaped antenna with novel broad banding techniques is proposed for Ultra-Wideband (UWB) applications. The initial design is taken as an elliptical radiator and techniques such as beveling of upper and lower half of elliptical radiator and introducing staircase in the coplanar ground plane of the antenna are used to significantly enhance the bandwidth. The proposed antenna has overall size of $50 \times 38 \times 1.6 \mathrm{~mm}^{3}$ and possess good radiation characteristics and return loss $<-10 \mathrm{~dB}$ in the whole $\mathrm{UWB}$ spectrum from $2.8 \mathrm{GHz}$ to $18 \mathrm{GHz}$. CST MICROWAVE STUDIO SUITE is employed for the design, optimization and simulation of antenna, which is based on method of finite integration technique (FIT). The performance of the proposed antenna is validated by comparing simulated and experimental results which exhibit that the designed antenna can be employed in various $U W B$ applications.
\end{abstract}

Index Terms: Coplanar Waveguide, Microstrip antenna, Planar antenna, Ultra-Wideband antenna.

\section{INTRODUCTION}

The Federal Communication Commission (FCC) issued a frequency spectrum of $3.1 \mathrm{GHz}-10.6 \mathrm{GHz}$ for unlicensed UWB technology in 2002. Since then UWB technology has achieved a lot of interest in academia, scientists and wireless industries. Some of the UWB applications are through-wall imaging, precise localization and high data rate communication [1].

One of the major challenges of micro-strip antenna design for UWB applications is achieving wide impedance bandwidth. To achieve ultra wideband performance some of the bandwidth enhancement techniques such as feed line with trident shape at one end alongside the patch [2], tapering and $\mathrm{T}$-shaping of ground along with notch of M-shape at the bottom of the patch [3], etching parasitic elements and cutting slots in the main patch [4], beveling of patch and etching semicircular slots in ground plane [5], using inverted L-strip on the patch [6] and staircase-shaped strip on the patch [7] have been proposed in literature. CPW-feed is mostly used in UWB antenna design, as it provides less dispersion, easy fabrication, wide bandwidth and lower loss at higher frequencies, which lead to better performance for UWB applications [8]. Various UWB antennas with shapes such as circular monopole patch [9-10], modified square patch [11] and modified rectangular patch [12] have been investigated.

In this paper, an elliptical antenna is modified by beveling

Revised Manuscript Received on July 09, 2019

Akanksha Upadhyay, Electronics and Communication Engineering Department, Thapar Institute of Engineering and Technology, Patiala, Punjab, India.

Rajesh Khanna, Electronics and Communication Engineering Department, Thapar Institute of Engineering and Technology, Patiala, Punjab, India. an elliptical patch and introducing staircase in the ground plane of CPW-feed for impedance bandwidth enhancement. The benefit of using staircase technique is that it offers increase in the overlapping of resonant frequencies on different levels etched on the ground and conserving the area around it. The tomb shaped UWB antenna radiates in a very wide impedance bandwidth from $2.8 \mathrm{GHz}-18 \mathrm{GHz}$ and fractional bandwidth is nearly $146 \%$. The proposed antenna is designed, simulated and fabricated to compare simulated and measured results and to investigate the characteristics of tomb shaped UWB antenna. This paper is divided into following sections; section II discusses about the antenna design. Section III presents the parametric study of the antenna. Section IV presents results and discussions of fabricated antenna. Finally the conclusions are drawn in section V.

\section{ANTENNA DESIGN}

Fig. 1 represents the configuration and parameters of the proposed antenna designed on FR4 substrate having height of $1.6 \mathrm{~mm}$.

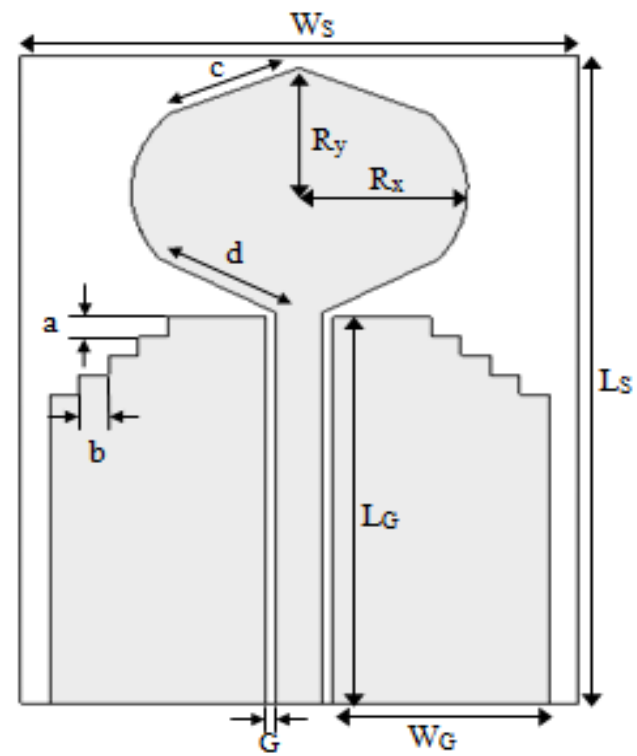

Fig. 1 Configuration of proposed UWB antenna.

Thickness of the copper material used for ground plane and radiating patch is $0.035 \mathrm{~mm}$. Width $\left(\mathrm{W}_{\mathrm{f}}\right)$ of CPW feed line is $3.2 \mathrm{~mm}$ and there is a spacing of $0.6 \mathrm{~mm}$ between the feed line and the coplanar ground plane. The proposed antenna has an overall compact size of $50 \times 38 \times 1.6 \mathrm{~mm}^{3}$. Each step of the staircase structure has identical height and width of ' $a$ ' and ' $b$ ' respectively. Table 1 shows the optimized dimensions of the tomb shaped UWB antenna. The final optimal dimensions of the antenna are derived using

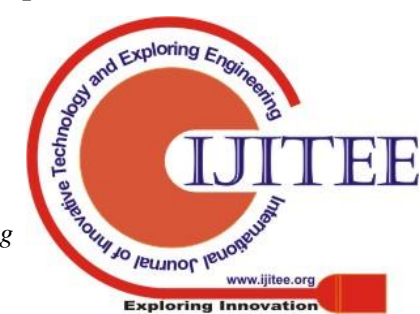


various structural modifications and parametric study as discussed next.

TABLE 1

DIMENSIONS OF THE TOMB SHAPED UWB ANTENNA

\begin{tabular}{cccc}
\hline \hline Parameters & Size $(\mathrm{mm})$ & Parameters & Size $(\mathrm{mm})$ \\
\hline $\mathrm{W}_{\mathrm{S}}$ & 38 & $\mathrm{G}$ & 0.6 \\
$\mathrm{~L}_{\mathrm{S}}$ & 50 & $\mathrm{a}$ & 1.5 \\
$\mathrm{R}_{\mathrm{x}}$ & 11.45 & $\mathrm{~b}$ & 2 \\
$\mathrm{R}_{\mathrm{y}}$ & 9.5 & $\mathrm{c}$ & 9.6 \\
$\mathrm{~L}_{\mathrm{G}}$ & 29.8 & $\mathrm{~d}$ & 8.9 \\
$\mathrm{~W}_{\mathrm{G}}$ & 14.75 & $\mathrm{~W}_{\mathrm{f}}$ & 3.2 \\
\hline \hline
\end{tabular}

The tomb shaped antenna is designed in three steps. Firstly, an elliptical patch antenna having coplanar ground is designed as shown in Fig. 2(a). Then upper and lower half of elliptical patch are beveled as shown in Fig. 2(b). Lastly a staircase is introduced in the ground planes of CPW feed of the beveled antenna as shown in Fig. 2(c).

The return loss curves for these three geometrical antenna configurations are compared in Fig. 3. The basic antenna is radiating from $2.8 \mathrm{GHz}-3.7 \mathrm{GHz}, 5.9 \mathrm{GHz}-7.2 \mathrm{GHz}, 9.07$ $\mathrm{GHz}-9.9 \mathrm{GHz}, 11.88 \mathrm{GHz}-13.2 \mathrm{GHz}, 14.9 \mathrm{GHz}-15.8 \mathrm{GHz}$. This implies that basic antenna structure is not radiating for entire impedance bandwidth ranging from $2.8 \mathrm{GHz}-18 \mathrm{GHz}$. When basic antenna is modified to form beveled antenna, it radiates for frequency band ranging from $2.5 \mathrm{GHz}-6.06 \mathrm{GHz}$ and $6.25 \mathrm{GHz}-18 \mathrm{GHz}$. On further modifying the beveled antenna by cutting out staircase structure from the ground planes to form final antenna an impedance bandwidth ranging from $2.8 \mathrm{GHz}-18 \mathrm{GHz}$ is achieved.

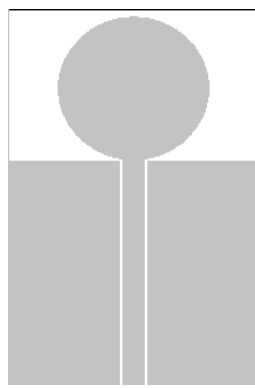

(a) Basic antenna

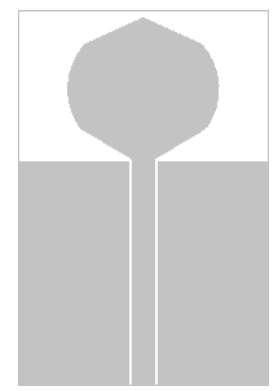

(b) Beveled antenna

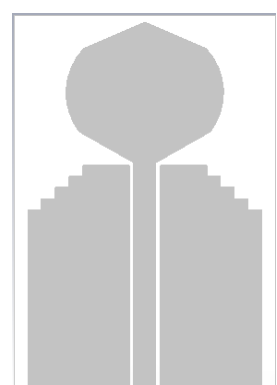

(c) Final antenna
Fig. 2 Geometrical variations in UWB antenna.

\section{PARAMETRIC STUDIES OF ANTENNA}

The effect caused by varying different dimensional parameters of final structure has been investigated and observed. During this parametric analysis, single dimension of the antenna is varied while keeping other dimensions fixed.

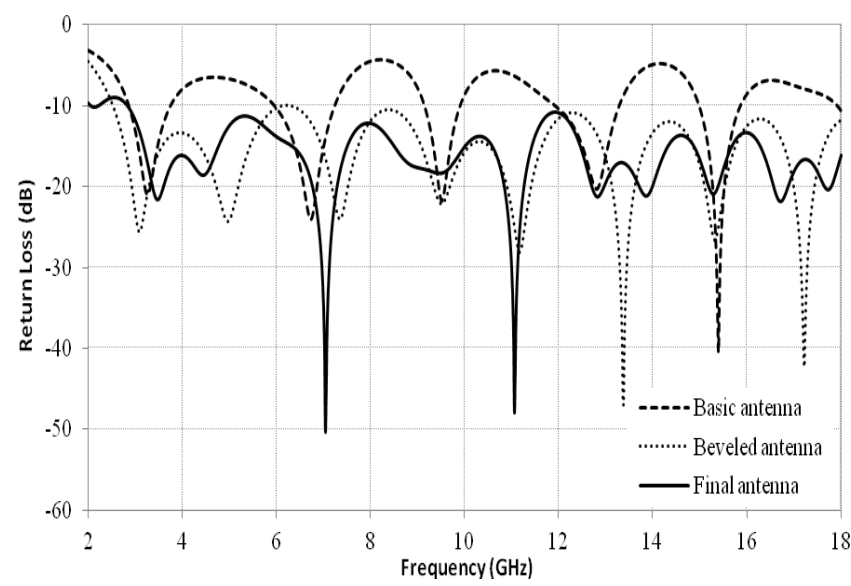

Fig. 3 Simulated Return Loss vs. Frequency curves for different antenna structures.

\section{A. Variation of radius of major and minor axis of the ellipse}

Radius of major axis of the ellipse $\left(\mathrm{R}_{\mathrm{x}}\right)$ is varied from 9.45 $\mathrm{mm}$ to $13.45 \mathrm{~mm}$ and return loss curves are plotted for comparison in Fig. 4. The optimum value of $R_{x}$ is $11.45 \mathrm{~mm}$. It can be seen that when $R_{x}$ is decreased from $11.45 \mathrm{~mm}$ to $9.45 \mathrm{~mm}$ the return loss values at $6.7 \mathrm{GHz}, 12.7 \mathrm{GHz}$ and 15.2 $\mathrm{GHz}$ degrades. Also when $\mathrm{Rx}$ is increased from $11.45 \mathrm{~mm}$ to $13.45 \mathrm{~mm}$ the return loss values degrades at $6.7 \mathrm{GHz}, 9.3$ $\mathrm{GHz}, 12.7 \mathrm{GHz}$ and $15.2 \mathrm{GHz}$.

Radius of minor axis of the ellipse $\left(\mathrm{R}_{\mathrm{y}}\right)$ is also varied from $9.25 \mathrm{~mm}$ to $9.75 \mathrm{~mm}$ in a step of $0.25 \mathrm{~mm}$ and return loss curves for different values of $\mathrm{R}_{\mathrm{y}}$ are plotted in Fig. 5. The optimum value of $R_{y}$ is $9.5 \mathrm{~mm}$. There is a slight change in return loss curve when $R_{y}$ is decreased from $9.5 \mathrm{~mm}$ to 9.25 $\mathrm{mm}$. Also, when $\mathrm{R}_{\mathrm{y}}$ is increased from $9.5 \mathrm{~mm}$ to $9.75 \mathrm{~mm}$ the return loss at lower band starting from $10 \mathrm{GHz}$ to $11 \mathrm{GHz}$ shows slight improvement but return loss at upper band degrades.

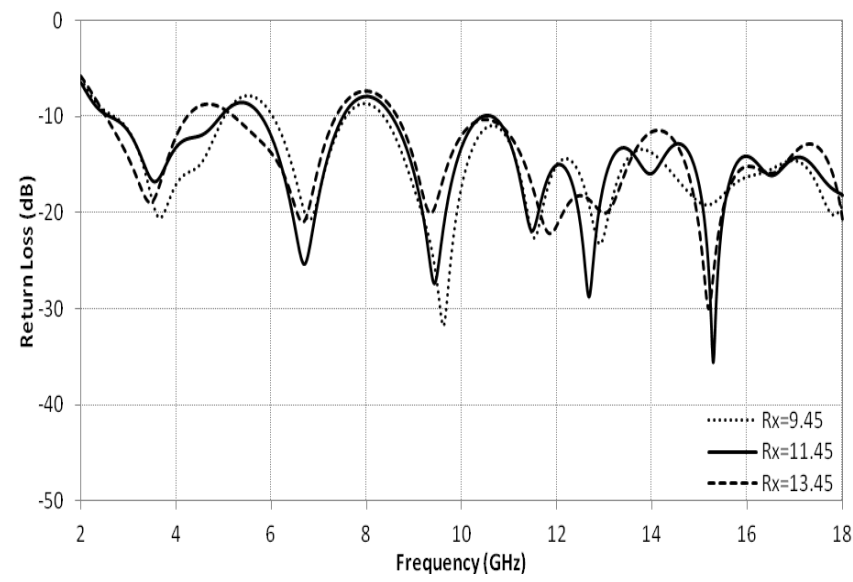

Fig. 4 Simulated Return Loss vs. Frequency curve for different values of $R_{x}$. 


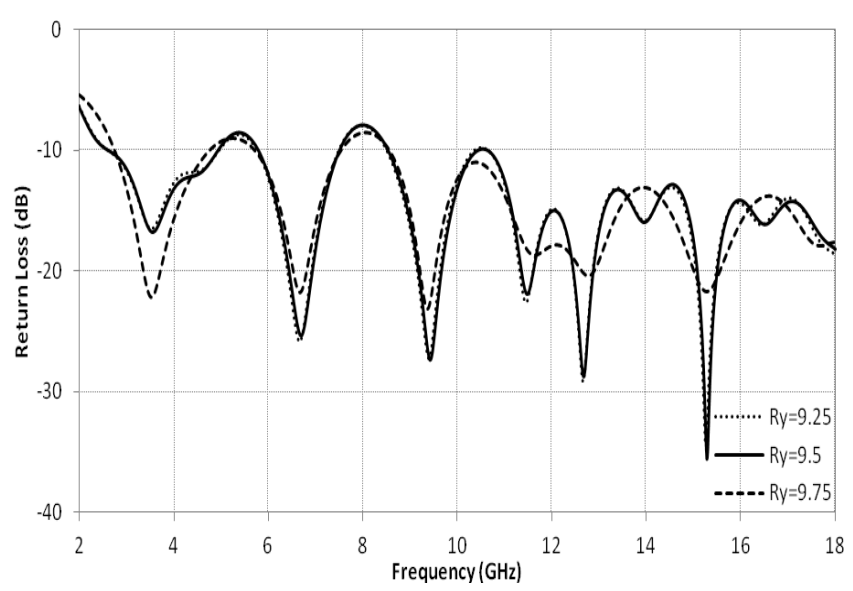

Fig. 5 Simulated Return Loss vs. Frequency curve for different values of $\mathrm{R}_{\mathrm{y}}$.

\section{B. Variation of beveling parameters ' $c$ ' and ' $d$ '}

Beveling length (c) is varied from $8.6 \mathrm{~mm}$ to $10.6 \mathrm{~mm}$ in a step of $1 \mathrm{~mm}$ and return loss curves are plotted for comparison in Fig. 6. The optimum value of 'c' is $9.6 \mathrm{~mm}$. It can be seen that when ' $c$ ' is increased from $9.6 \mathrm{~mm}$ to $10.6 \mathrm{~mm}$ return loss values degrades at $3.1 \mathrm{GHz}, 6.96 \mathrm{GHz}, 9.37 \mathrm{GHz}, 11.56 \mathrm{GHz}$ and $17.23 \mathrm{GHz}$. There is a slight impact of decreasing the length of ' $\mathrm{c}$ ' from $9.6 \mathrm{~mm}$ to $8.6 \mathrm{~mm}$. Hence, return loss curves for $\mathrm{c}=8.6 \mathrm{~mm}$ and $9.6 \mathrm{~mm}$ are almost overlapping.

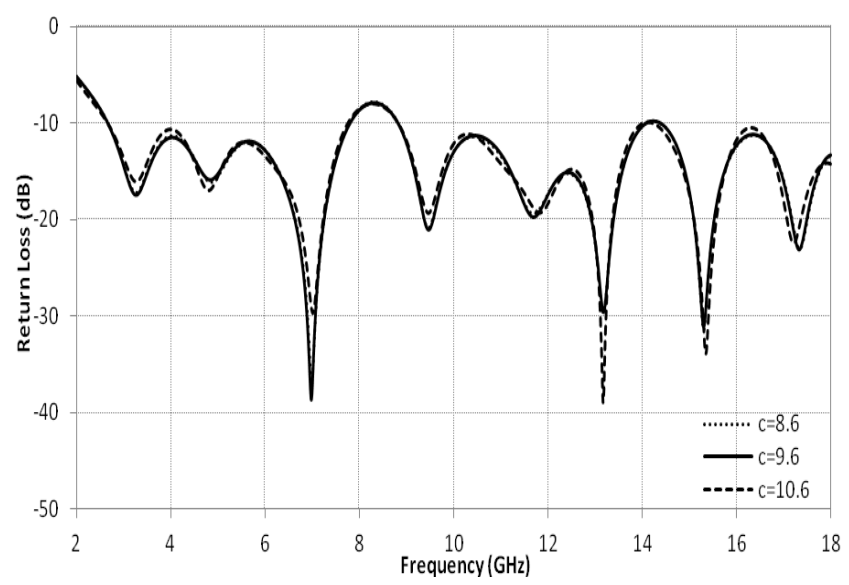

Fig. 6 Simulated Return Loss vs. Frequency curve for different values of ' $c$ '.

Beveling length (d) is varied from $6.9 \mathrm{~mm}$ to $10.9 \mathrm{~mm}$ and return loss curves are plotted for comparison in Fig. 7. The optimum value of ' $\mathrm{d}$ ' is taken as $8.9 \mathrm{~mm}$. When ' $\mathrm{d}$ ' is decreased from $8.9 \mathrm{~mm}$ to $6.9 \mathrm{~mm}$ the return loss degrades at various frequencies. Also when 'd' is increased from $8.9 \mathrm{~mm}$ to $10.9 \mathrm{~mm}$ return loss degrades at various frequencies of the UWB antenna like at $3.04 \mathrm{GHz}, 6.01 \mathrm{GHz}, 7.27 \mathrm{GHz}, 8.41$ $\mathrm{GHz}, 11.12 \mathrm{GHz}, 13.3 \mathrm{GHz}$ and $15.26 \mathrm{GHz}$.

\section{Variation of beveling parameters ' $a$ ' and ' $b$ '}

Length of staircase (a) is varied from $0.5 \mathrm{~mm}$ to $2.5 \mathrm{~mm}$ and return loss curves are plotted for comparison in Fig. 8. The optimum value of ' $a$ ' is taken as $1.5 \mathrm{~mm}$. It can be seen that as the value of ' $a$ ' is decreased from $1.5 \mathrm{~mm}$ to $0.5 \mathrm{~mm}$, return loss of the antenna degrades at $4 \mathrm{GHz}, 7.04 \mathrm{GHz}, 8.44 \mathrm{GHz}$, $11 \mathrm{GHz}, 12.75 \mathrm{GHz}, 13.8 \mathrm{GHz}, 16.6 \mathrm{GHz}$ and $17.6 \mathrm{GHz}$. Also when 'a' is increased from $1.5 \mathrm{~mm}$ to $2.5 \mathrm{~mm}$, return loss of the antenna degrades at $4.49 \mathrm{GHz}, 5.35 \mathrm{GHz}, 7.04 \mathrm{GHz}, 9.35$ $\mathrm{GHz}, 11 \mathrm{GHz}, 12.7 \mathrm{GHz}$ and $16.6 \mathrm{GHz}$.

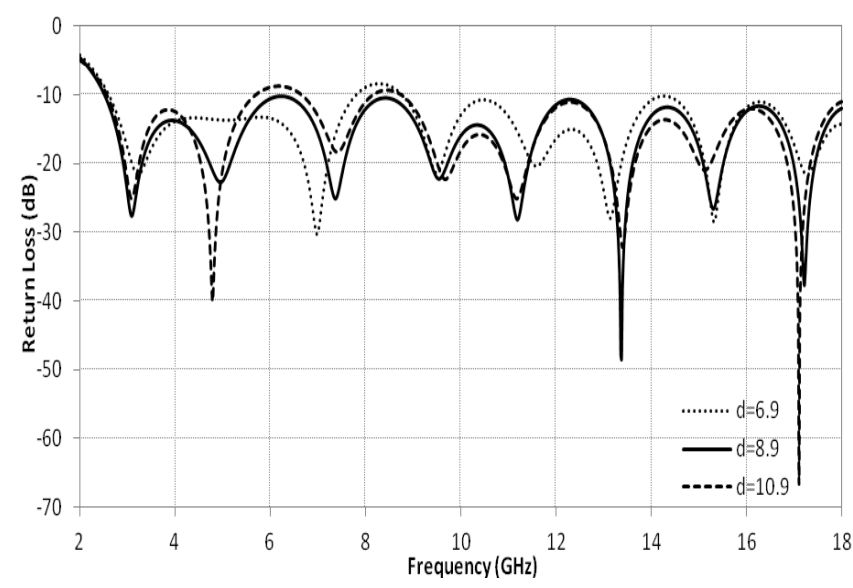

Fig. 7 Simulated Return Loss vs. Frequency curve for different values of 'd'.

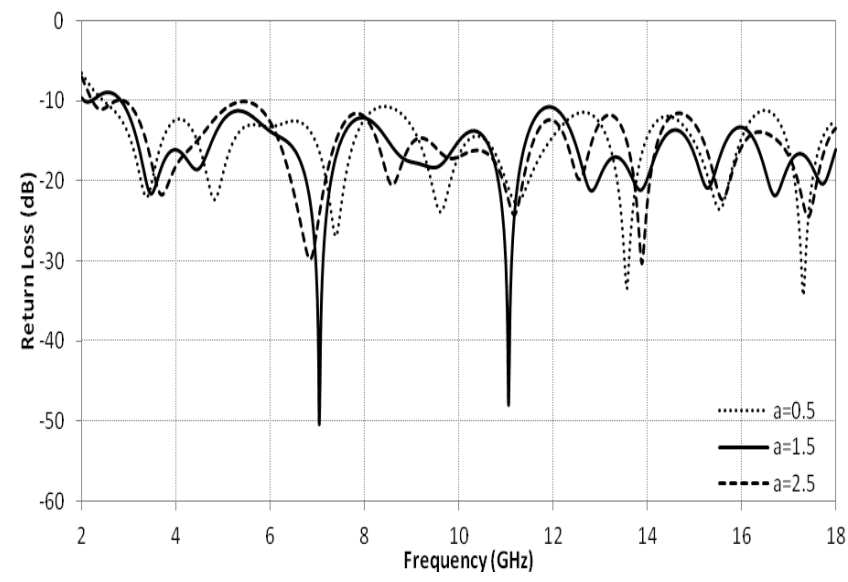

Fig. 8 Simulated Return Loss vs. Frequency curve for different values of ' $a$ '.

Width of staircase (b) is varied from $1.5 \mathrm{~mm}$ to $2.5 \mathrm{~mm}$ and return loss curves are plotted for comparison in Fig. 9. The optimum value of ' $b$ ' is taken as $2 \mathrm{~mm}$. It can be seen that when ' $b$ ' is decreased from $2 \mathrm{~mm}$ to $1.5 \mathrm{~mm}$ the return loss value degrades at $4.5 \mathrm{GHz}, 7.04 \mathrm{GHz}, 9.21 \mathrm{GHz}$ and 16.83 GHz. Also when ' $b$ ' is increased from $2 \mathrm{~mm}$ to $2.5 \mathrm{~mm}$ the return loss values degrades at $4.2 \mathrm{GHz}, 7 \mathrm{GHz}, 11 \mathrm{GHz} 12.7$ $\mathrm{GHz}, 13.9 \mathrm{GHz}$ and $17.64 \mathrm{GHz}$.

\section{RESULTS AND DISCUSSION}

The tomb shaped UWB antenna was fabricated according to the dimensions given in the Table 1 using FR4 substrate. Fabricated tomb shaped UWB antenna is shown in Fig. 10 Measurement of return loss and hence impedance bandwidth of the proposed antenna is done with a KEYSIGHT E5063A $(100 \mathrm{KHz}-18 \mathrm{GHz})$ vector network analyzer (VNA).

The measured and simulated return loss curves of the tomb shaped UWB antenna are compared in Fig. 11. After observing both return loss curves it is seen that simulated and measured results are in conformity with each other to a large extent. 


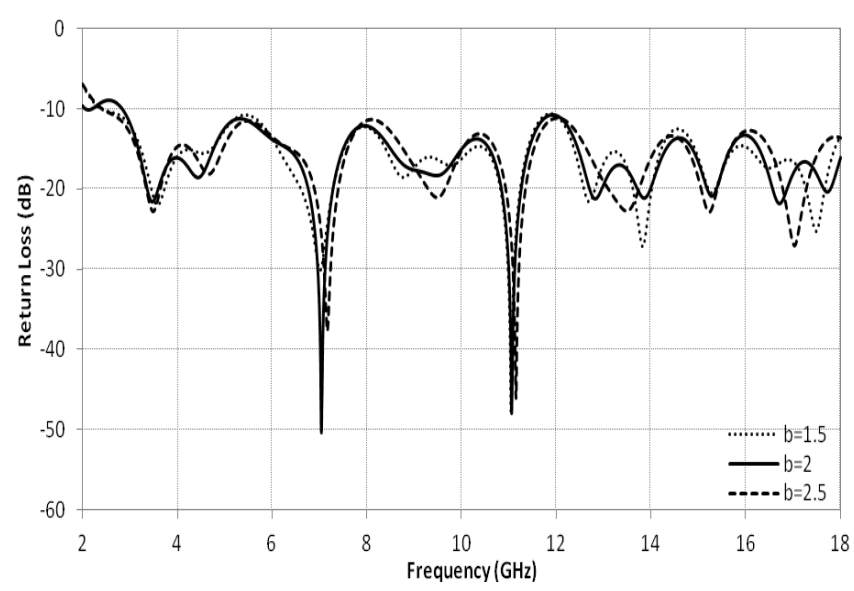

Fig. 9 Simulated Return Loss vs. Frequency curve for different values of ' $b$ '.

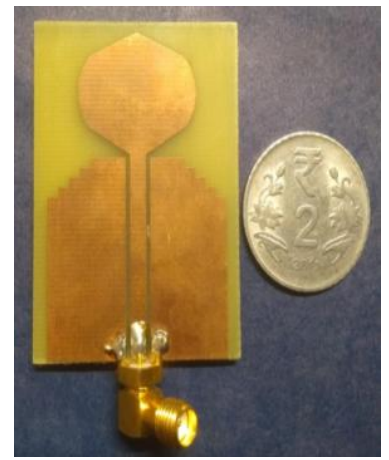

Fig. 10 The fabricated antenna.

The small deviation of measured result from simulated result is because of fabrication tolerance, SMA soldering and SMA connector. The fabricated antenna shows an ultra wideband performance from $2.8 \mathrm{GHz}$ to $18 \mathrm{GHz}$.

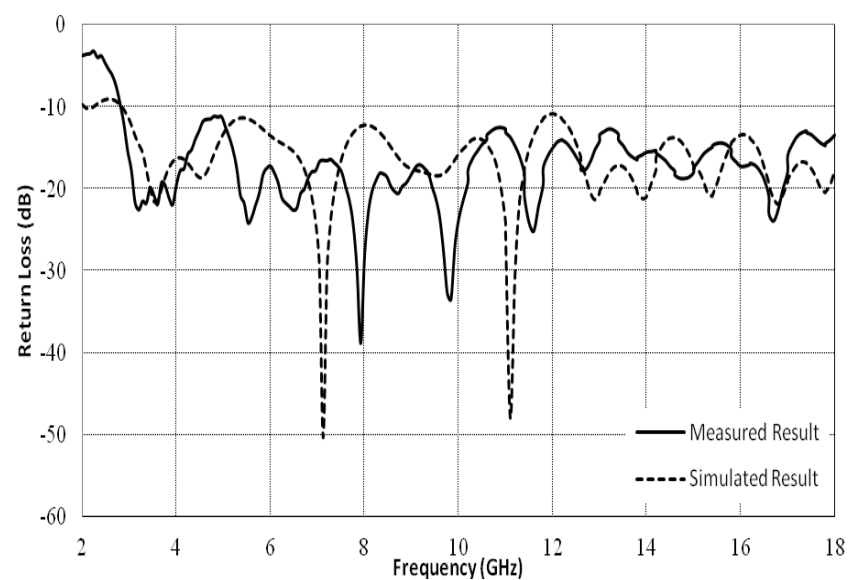

Fig. 11 Simulated and measured Return Loss curves of tomb shaped UWB antenna.

Fig. 12 demonstrates the surface current distributions of the tomb shaped antenna at $5 \mathrm{GHz}, 11 \mathrm{GHz}$, and $17 \mathrm{GHz}$. We can see that as the operating frequency increases, the current density slowly decreases in the staircase-shaped ground. In almost whole of the frequency range of $2.8 \mathrm{GHz}-18 \mathrm{GHz}$, the lower half of the beveled elliptical patch carries the current. Moreover, the upper half of beveled patch carries current at higher frequencies and has the most effect on higher frequencies.
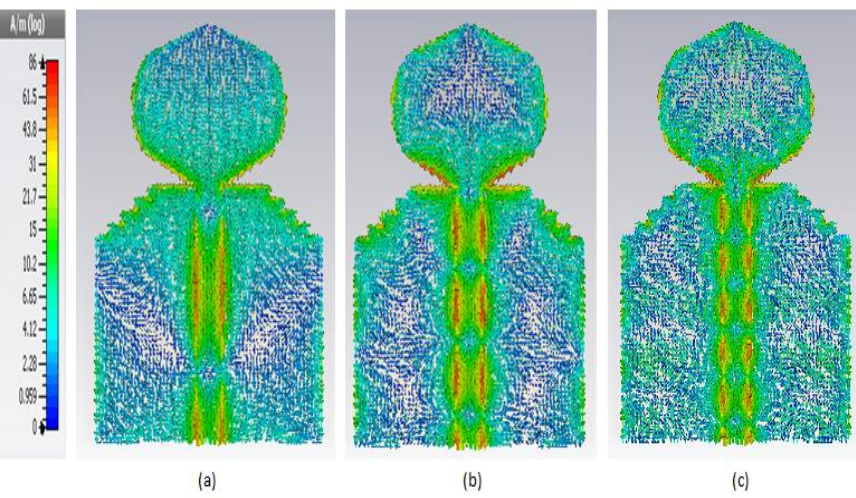

(b)

(c)

Fig. 12 Surface current distribution on the antenna at (a) 5, (b) 11, and (c) $17 \mathrm{GHz}$.

The simulated E-plane and H-plane radiation patterns showing co-polarisation and cross-polarisation of tomb shaped antenna at $3 \mathrm{GHz}, 7 \mathrm{GHz}$ and $17 \mathrm{GHz}$ are demonstrated in Fig. 13. H-plane has an omnidirectional radiation pattern while E-plane shows monopole like radiation pattern. As the frequency increases form $3 \mathrm{GHz}$ to $17 \mathrm{GHz}$ the $\mathrm{H}$-plane cross-polarization component starts increasing.

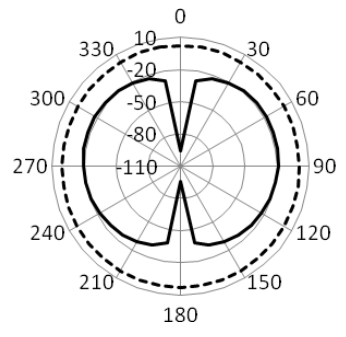

(a) H-Plane at $3 \mathrm{GHz}$

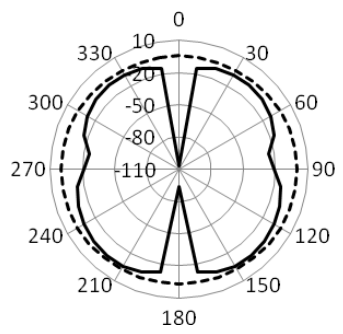

(c) H-Plane at $7 \mathrm{GHz}$

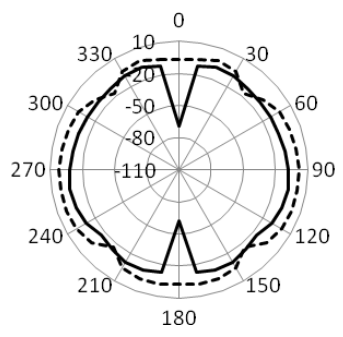

(e) H-Plane at $17 \mathrm{GHz}$

- - - - Co-Polarisation

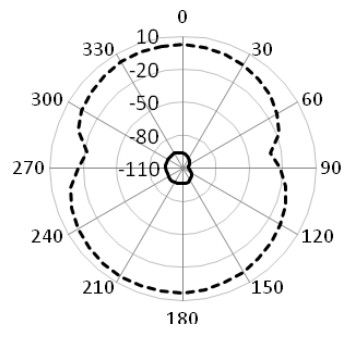

(b) E-Plane at $3 \mathrm{GHz}$

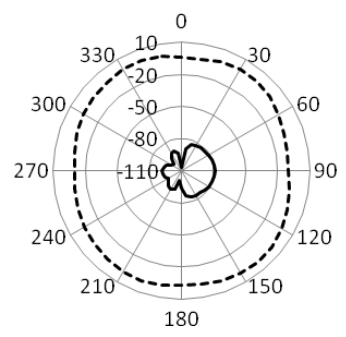

(d) E-Plane at $7 \mathrm{GHz}$

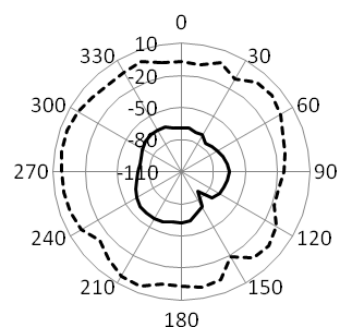

(f) E-Plane at $17 \mathrm{GHz}$ Cross-Polarisation
Fig. 13 Measured co-polarisation and simulated cross-polarization radiation patterns at various frequencies for the tomb shaped UWB microstrip antenna.

It is observed from Fig. 14 that measured Gain (in range of 
$2.8 \mathrm{GHz}-18 \mathrm{GHZ}$ ) of tomb shaped antenna is varying from $2.5 \mathrm{dBi}$ to $4.27 \mathrm{dBi}$.

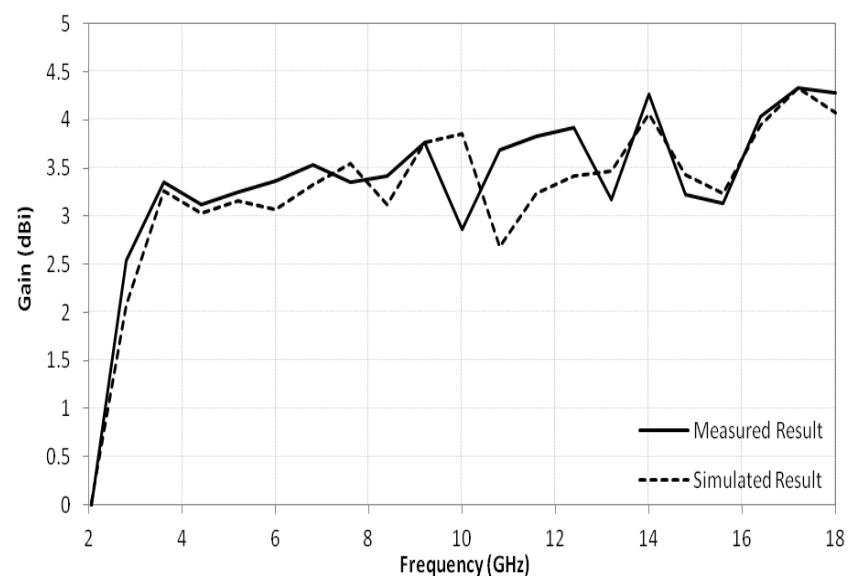

Fig. 14 Gain vs. frequency plot for the tomb shaped UWB microstrip antenna.

The comparison of proposed tomb shaped antenna with existing UWB antennas is given in Table 2.

TABLE 2

COMPARISON OF PROPOSED ANTENNA WITH EXISTING UWB ANTENNAS

\begin{tabular}{ccc}
\hline \hline Antenna & $\begin{array}{c}\text { Antenna } \\
\text { Dimension }\left(\mathrm{mm}^{2}\right)\end{array}$ & $\begin{array}{c}\text { Bandwidth } \\
(\mathrm{GHz})\end{array}$ \\
\hline Ref. [13] & $106 \times 140$ & $0.97-8.98$ \\
Ref. [14] & $50 \times 50$ & $2.5-12$ \\
Ref. [15] & $60 \times 50$ & $2-10.6$ \\
Ref. [16] & $50 \times 48$ & $2.74-11$ \\
Ref. [17] & $53 \times 53$ & $2.2-12$ \\
Ref. [18] & $85 \times 85$ & $2.83-18.2$ \\
Ref. [19] & $50 \times 50$ & $2.6-10.8$ \\
Ref. [8] & $60 \times 60$ & $2.6-13.1$ \\
Ref. [20] & $50 \times 50$ & $1.5-11$ \\
Ref. [21] & $50 \times 46$ & $3.5-10.6$ \\
Proposed Antenna & $50 \times 38$ & $2.8-18$ \\
\hline \hline
\end{tabular}

\section{CONCLUSION}

A tomb shaped CPW fed printed monopole antenna for different UWB applications has been designed, simulated, fabricated and analyzed. It can be seen from the results that by beveling upper and lower half of elliptical patch and using staircase technique in ground, a large impedance bandwidth from $2.8 \mathrm{GHz}$ to $18 \mathrm{GHz}$ for return loss $<-10 \mathrm{~dB}$, is achieved. Hence from the measured results it can be concluded that the proposed antenna is fit for UWB applications.

\section{REFERENCES}

1. Federal Communications Commission: First report and order in the matter of revision of part 15 of the commission's rules regarding ultra-wideband transmission systems. ET-Docket 98-153, FCC 02-48, 2002.

2. S. R. Emadian, C. Ghobadi, J. Nourinia, M. H. Mirmozafari and J. Pourahmadazar, "Bandwidth Enhancement of CPW-Fed Circle-Like Slot Antenna With Dual Band-Notched Characteristic," in IEEE Antennas and Wireless Propagation Letters, vol. 11, 2012, pp. 543-546.

3. C. Deng, Y. Xie and P. Li, "CPW-Fed Planar Printed Monopole Antenna With Impedance Bandwidth Enhanced," in IEEE Antennas and Wireless Propagation Letters, vol. 8, 2009, pp. 1394-1397.
4. K. Chung, T. Yun and J. Choi, "Wideband CPW-fed monopole antenna with parasitic elements and slots," in Electronics Letters, vol. 40, no. 17, 2004, pp. 1038-1040.

5. S. R. Emadian and J. Ahmadi-Shokouh, "Very Small Dual Band-Notched Rectangular Slot Antenna With Enhanced Impedance Bandwidth," in IEEE Transactions on Antennas and Propagation, vol. 63, no. 10 2015, pp. 4529-4534,.

6. A. K. Gautam, S. Yadav and B. K. Kanaujia, "A CPW-Fed Compact UWB Microstrip Antenna," in IEEE Antennas and Wireless Propagation Letters, vol. 12, 2013, pp. 151-154.

7. Z. J. Tang, J. Zhan and H. L. Liu, "Compact CPW-fed antenna with two asymmetric U-shaped strips for UWB communications," in Electronics Letters, vol. 48, no. 14, 2012, pp. 810-812.

8. J. Pourahmadazar, C. Ghobadi, J. Nourinia, N. Felegari and H. Shirzad, "Broadband CPW-Fed Circularly Polarized Square Slot Antenna With Inverted-L Strips for UWB Applications," in IEEE Antennas and Wireless Propagation Letters, vol. 10, 2011, pp. 369-372.

9. N. Chen and Y. Liang, "Coplanar-Waveguide Fed Circular Disc Monopole Antenna with Improved Radiation Characteristics," in The Second European Conference on Antennas and Propagation, Edinburgh, 2007, pp. 1-6.

10. Chenn-Ming Lee, Tzong Chee Yo, Cheng Hsing Luo, Chih-Ho Tu and Ying-Zong Juang, "Broadband disk monopole antenna with a circular CPW-feeding line," in IEEE Antennas and Propagation Society International Symposium, Honolulu, HI, 2007, pp. 773-776.

11. N. Ojaroudi and M. Ojaroudi, "Novel Design of Dual Band-Notched Monopole Antenna With Bandwidth Enhancement for UWB Applications," in IEEE Antennas and Wireless Propagation Letters, vol. 12, 2013, pp. 698-701.

12. R. Addaci, N. Hamdiken, T. Fortaki, F. Ferrero, D. Seetharamdoo and R Staraj, "Simple bandwidth-enhancement technique for miniaturised low-profile UWB antenna design," in Electronics Letters, vol. 50, no. 22, 2014, pp. 1564-1566.

13. Xian-Ling Liang, Shun-Shi Zhong and Feng-Wei Yao, "Compact UWB tapered-CPW-fed planar monopole antenna," in Asia-Pacific Microwave Conference Proceedings, Suzhou, 2005, pp. 3.

14. I. B. Vendik, A. Rusakov, K. Kanjanasit, J. Hong and D. Filonov, "Ultrawideband (UWB) Planar Antenna with Single-, Dual-, and Triple-Band Notched Characteristic Based on Electric Ring Resonator," in IEEE Antennas and Wireless Propagation Letters, vol. 16, 2017, pp 1597-1600.

15. Anju A. Chandran, and Shiney Thankachan, "Triple frequency notch in UWB antenna with single ring SRR loading," in Proceedings of Computer Science, vol. 93, 2016, pp. 94-100.

16. L. Peng, B. Wen, X. Li, X. Jiang and S. Li, "CPW Fed UWB Antenna by EBGs With Wide Rectangular Notched-Band," in IEEE Access, vol. 4, 2016, pp. 9545-9552.

17. Y. Kim and D. -Kwon, "CPW-fed right-angled dual tapered notch antenna for ultra-wideband communication," in Electronics Letters vol. 41 , no. 12,2015 , pp. 674-675.

18. A. Dastranj and H. Abiri, "Bandwidth Enhancement of Printed E-Shaped Slot Antennas Fed by CPW and Microstrip Line," in IEEE Transactions on Antennas and Propagation, vol. 58, no. 4, 2010, pp. 1402-1407.

19. J. Y. Siddiqui, C. Saha and Y. M. M. Antar, "Compact SRR Loaded UWB Circular Monopole Antenna With Frequency Notch Characteristics," in IEEE Transactions on Antennas and Propagation, vol. 62 , no. 8,2014 , pp. 4015-4020.

20. D. M. Elsheakh and E. A. Abdallah, "Ultra-wide-bandwidth (UWB) microstrip monopole antenna using split ring resonator (SRR) structure," in International Journal of Microwave and Wireless Technologies, vol. 10, no. 1, 2018, pp. 123-132.

21. M. S. A. Rani, S. K. A. Rahim, H. Rezaie, F. D. Dahalan, M. I. Sabran, M. Z. M. Nor, and A. Zainal, "Directional UWB antenna with a parabolic ground structure and split ring resonator for a $5.8 \mathrm{GHz}$ band notch," in Journal of Electromagnetic Waves and Applications, vol. 27, no. 1,2013 , pp. 14-22. 


\section{AUTHORS PROFILE}

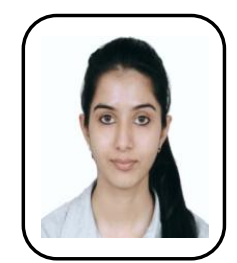

Akanksha Upadhyay received B. Tech. degree in ECE in 2016 from Punjab Technical University and M.E. from Thapar Institute of Engineering and Technology, Patiala. Presently she is pursuing Ph.D from Thapar Institute of Engineering and Technology, Patiala. Her main research interest includes microstrip patch antennas and VLSI interconnects.

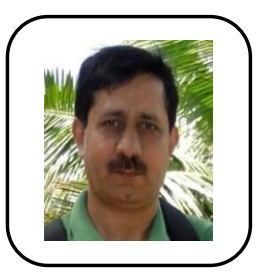

Rajesh Khanna received a B.Sc. (Engg.) degree in ECE in 1988 from REC, Kurukshetra and M.E. degree in 1998 from IISc. Bangalore. He was with Hartron R\&D center till 1993. Until 1999, he was in AIR as Assistant Station Engineer. Presently, he is working as Professor in the ECED at Thapar Institute of Engineering and Technology, Patiala. He has published 80 papers in National and International journal/Conferences. He has worth Rs 1.5 crore projects to his credit. His main research interest includes antennas, Wireless Communication, MIMO systems. 